\title{
Tabaquismo pasivo en el hogar: una invitación a la reflexión
}

\author{
Petra María Cortés Durán y Beatriz López Serrano
}

Médicos de Familia.

Centro de Salud María Ángeles López Gómez.

Leganés. Madrid (España).

\section{Correspondencia:}

Petra María Cortés Durán. Centro de Salud María Ángeles López Gómez. C/ María Ángeles López Gómez, 2. C.P. 28915. Legánes. Madrid (España).

Correo electrónico: artep03@hotmail.com.

Recibido el 4 de junio de 2014. Aceptado para su publicación el 11 de julio de 2014 .

\section{RESUMEN}

Presentamos el caso de una paciente expuesta a humo de tabaco ambiental en su hogar durante más de 35 años en un reducido espacio. Fue diagnosticada de una tumoración renal (carcinoma de células de transición de pelvis renal), siendo una causa de este tipo de tumores el consumo de tabaco. Pretendemos generar una reflexión sobre el tabaquismo pasivo en el hogar e incorporar nuestro consejo antitabaco en este sentido a nuestros pacientes. Según datos del Ministerio de Sanidad en España, se estima que la exposición al aire contaminado por el humo del tabaco en personas no fumadoras causa, cada año, la muerte alrededor de 1.498 personas.

Palabras Clave. Tabaquismo pasivo. Neoplasias Renales. Atención Primaria de Salud.

\section{ABSTRACT}

Passive tobacco exposure in the home: an invitation for thinking

The present is the case of a female patient exposed to environmental tobacco smoke in her home for more than 35 year-old in a reduced space. She was diagnosed a renal tumor (transitional cells carcinoma of the renal pelvis), being this type of tumor caused by tobacco consumption. Our intention is to generate some thinking around passive tobacco exposure in the home while incorporating our anti-smoking advice to this regard to our patients. According to data from the Spanish Ministry of Health, the exposure of non-smokers to air polluted by tobacco smoke causes 1,498 deaths each year.

Key words: Smoking, Passive. Kidney Neoplasms. Primary Health Care.

\section{INTRODUCCIÓN}

Desde hace tiempo, se sospecha que el tabaquismo pasivo o exposición al humo de tabaco ambiental es la causa de numerosa patología. Los primeros estudios importantes que existen sobre tabaquismo pasivo y cáncer de pulmón en no fumadores se publicaron en 1981. En 1986, diversas sociedades americanas apoyaron esta relación, y en los años 90 se relacionó el tabaquismo pasivo con la enfermedad coronaria1. En 1986 la International Agency for Research on Cancer (IARC) confirma la relación del cáncer de pelvis renal con el consumo del tabaco. El humo del tabaco es el contaminante ambiental producido por el hombre que causa más muertes.

Los fumadores activos inhalan el humo de la corriente principal, el humo que se aspira directamente del extremo del cigarrillo; los fumadores pasivos inhalan el humo del ambiente procedente de la corriente secundaria o lateral del cigarrillo, producto del cigarrillo que arde sin llama y parte de la corriente principal que se exhala. Esta corriente es más rica en muchos de los constituyentes perjudiciales del humo que la corriente principal; sin embargo, su efecto se diluye en parte en el aire del ambiente, por lo que la exposición es menor. El National Research Council americano concluyó en 1986 que los fumadores pasivos absorben el equivalente a 0,1-1 cigarrillo al día, según se evidencia por sus concentraciones de cotinina urinaria (metabolito de la nicotina). 
En 1997 Hackshaw afirma la relación dosis-respuesta con el número de cigarrillos fumados por el cónyuge y los años de exposición². El sistema genitourinario está expuesto a las toxinas del tabaco por la excreción e irritación prolongada de compuestos cancerígenos por la orina y por el contenido en sangre de los mismos, como el cianuro de hidrógeno, el monóxido de carbono y óxidos de nitrógeno. Estudios con biomarcadores de exposición y dosis documentan la absorción de los componentes del humo de tabaco ambiental por parte de los fumadores pasivos. En España el tabaquismo pasivo es la tercera causa de muerte evitable, con 3.200 fallecimientos, después del tabaquismo activo (53.000 fallecimientos) y el abuso de alcohol (8.200 fallecimientos), y por encima de la mortalidad por accidentes de tráfico $(2.460$ víctimas en 2009), según datos del Ministerio de Sanidad. Diversos autores consideran que las principales causas de muerte por tabaquismo pasivo son la cardiopatía isquémica, el cáncer de pulmón y la muerte súbita del lactante ${ }^{3}$.

El cáncer de riñón se origina en el cuerpo del riñón y en su pelvis. Además se ha visto un mayor riesgo relativo en mujeres que en hombres para tener un tumor renal. Esta diferencia podría estar en relación con la potencial interacción entre las hormonas sexuales y los carcinógenos ${ }^{4}$. La pelvis renal y los uréteres están revestidos con células de transición; el cáncer de estas células es el más común de los tumores renales, constituyendo el $7 \%$ de los tumores en humanos.

Existen otras causas que se asocian a la etiología de estos tumores, como el aumento de la ingesta de grasa y colesterol y la exposición a otras sustancias tóxicas, como las utilizadas en la manipulación del cuero, fibras textiles, materiales plásticos y cauchos, pero sobre todo la causa que más se repite es el tabaco principalmente y particularmente las aminas aromáticas de este; además parece existir una sensibilidad variable a estas sustancias que depende del genotipo de cada persona ${ }^{5}$. El consumo de tabaco duplica la probabilidad de padecer un carcinoma renal y contribuye a su desarrollo en casi un tercio de los pacientes ${ }^{6}$. El síntoma más habitual en pacientes con carcinoma de células transicionales es la hematuria.

\section{CASO CLÍNICO}

Se trata de una paciente de 57 años de edad con antecedente de carcinoma ductal de mama izquierda diagnosticado en 1999 y de carcinoma ductal "in situ" de mama derecha en 2002, sin datos de recidiva desde entonces, trabajadora en una lavandería hospitalaria como planchadora. La paciente nunca ha fumado, pero convive en un piso de 65 metros cuadrados con su marido, fumador de 30 cigarrillos diarios (variedad negro), con el que vive desde hace 35 años, su hijo e hija, ambos también fumadores. El hijo es fumador de 20 cigarrillos diarios, con el que ha convivido 31 años; y la hija es fumadora de 10 cigarrillos diarios, con la que ha convivido 25 años. Todos fumaban dentro del piso, ninguno salía a la terraza a fumar.

Consulta por hematuria franca que lo relaciona con dolor lumbar de carácter mecánico. A la exploración física no se objetiva ningún dato relevante, no se palpa masa en fosas renales. Se solicita urocultivo, ecografía y analítica (hematología y bioquímica general). La analítica fue normal, excepto proteinuria, y el urocultivo fue negativo. La ecografía fue informada como "sin alteraciones significativas, excepto ligera ectasia en grupo calicial superior derecho". Decidimos que ante una hematuria con proteinuria positiva (confirmada en orina de 24 horas), lo derivábamos al servicio de Nefrología para completar estudio y seguimiento.

Se le practicó una segunda ecografía, dando como resultado la misma conclusión que la primera (realizada con 6 meses de diferencia), al igual que una urografía intravenosa donde se visualiza dilatación pielocalicial y del uréter derecho. En la Tomografía Computerizada (TC) se encuentran los mismos hallazgos, sin observar causa obstructiva que justifique esa dilatación. En la tercera ecografía (meses después) se visualiza contenido ecogénico en el sistema pielocalicial de riñón derecho (figura 1), solicitando por ello TC de nuevo, donde se encuentra una imagen con densidad de partes blandas que afecta al infundíbulo superior y pelvis renal en su porción intrarrenal, produciendo dilatación del cáliz superior. La lesión capta y es compatible con carcinoma de células transicionales en sistema colector derecho, infundíbulo superior y parte de pelvis renal (figura 2). Las citologías de orina fueron positivas. La paciente fue sometida a una nefrectomía y ureterectomía laparoscópica derecha.

En la anatomía patológica se confirma carcinoma de células transicionales de pelvis renal, con focos de carcinoma mucinoso que afecta a pelvis, infiltra parénquima y respeta bordes ureterales, estadio teórico pT3. Casi dos años más tarde, en TC torácico se confirman lesiones ocupantes de espacio en hígado compatibles con metástasis hepáticas y óseas. 


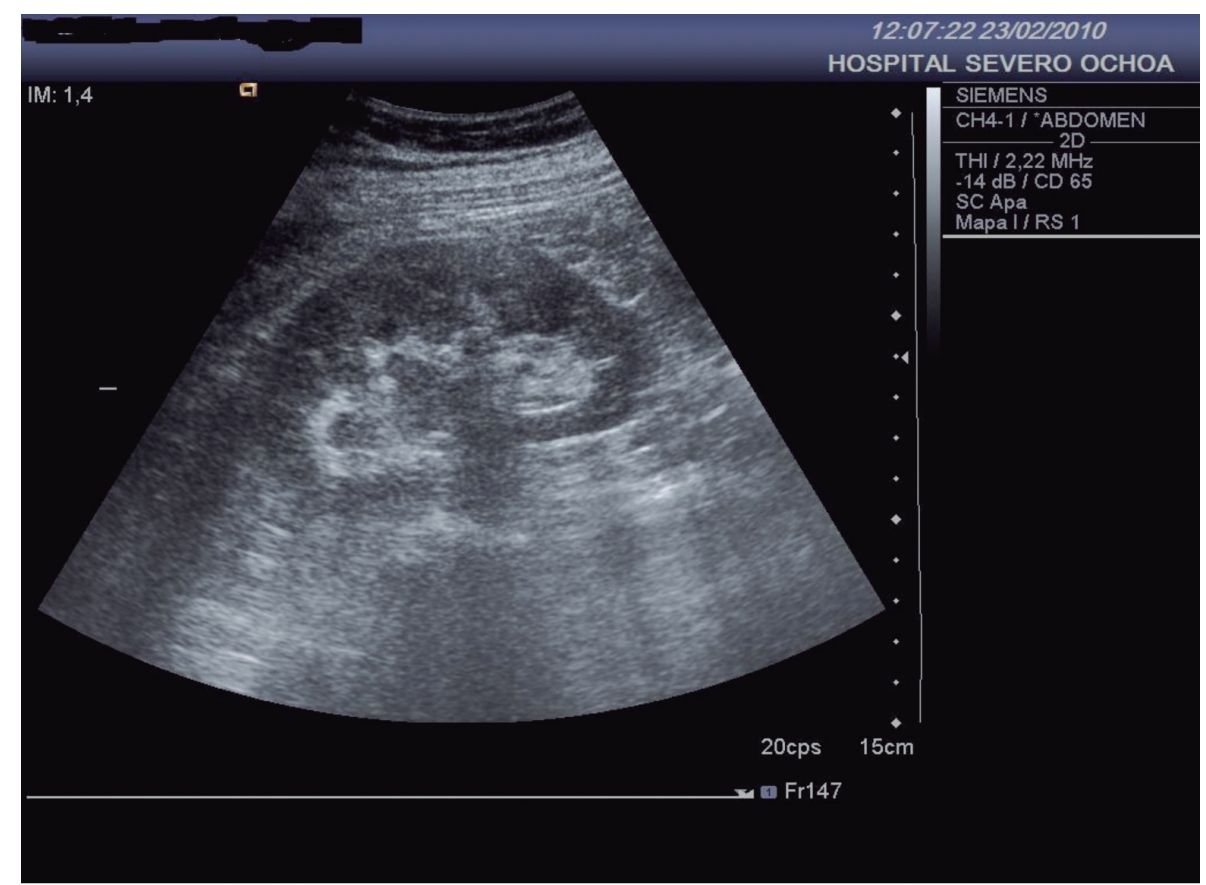

Figura 1. Ecografía de riñón derecho en la que se visualiza contenido ecogénico en el sistema pielocalicial

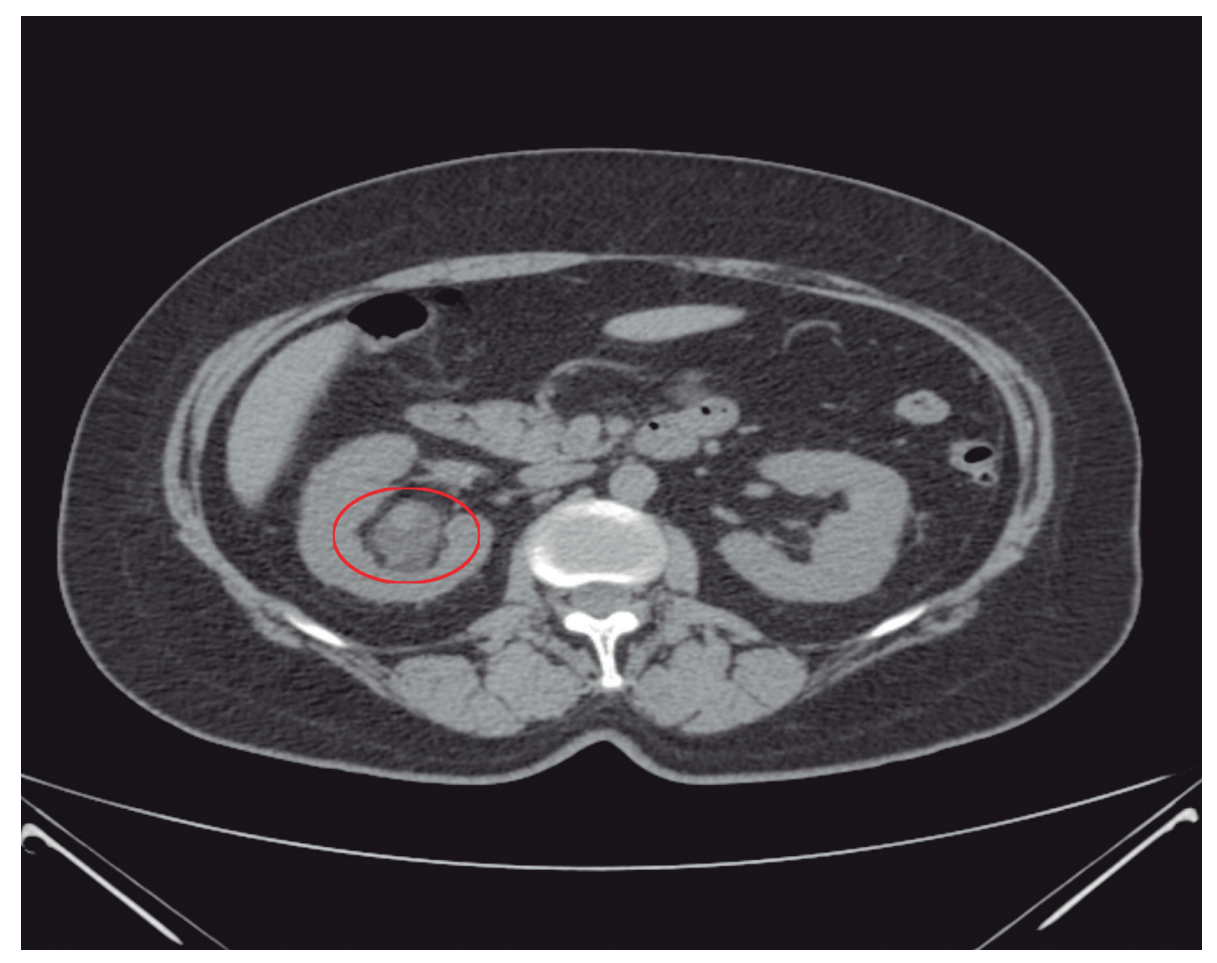

Figura 2. Tomografía computerizada abdominal en la que se aprecia una imagen con densidad de partes blandas que afecta al infundíbulo superior y pelvis renal derecha en su porción intrarrenal, produciendo dilatación del cáliz superior (círculo rojo)

\section{DISCUSIÓN}

La relación tabaco-cáncer renal y tabaco-cáncer de mama, probablemente en este caso no se pueda demostrar, pero sí nos invita a una reflexión sobre el consumo de tabaco en el hogar. Esta paciente nunca fumó de forma activa, pero las tres personas con las que convivió un gran número de años, sí. Su pareja concretamente fumaba tabaco negro, más relacionado con las neoplasias renales. Probablemente esta paciente tenga oncogenes en su bagaje genético, ya que entre sus antecedentes personales tiene un carcinoma de mama (además bilateral), aunque no en sus antecedentes familiares o quizás ha tenido estos antecedentes por el tóxico con el que convivía. 
La paciente no había sido expuesta a ningún tóxico laboral y en las analíticas las cifras de colesterol estaban en el límite (226 mg/dl); por lo tanto, el tabaquismo pasivo era el antecedente que prevalecía como factor de riesgo principalmente, ya que existen evidencias de esta noxa como causa de carcinoma renal y también de carcinoma de mama ${ }^{7,8}$.

El grado de contaminación del ambiente de humo de tabaco depende del número de fumadores activos y del tamaño y ventilación de la habitación (recordemos las condiciones de convivencia de la paciente). La toxicidad de la corriente secundaria (lateral) del cigarrillo es tanta como la de la principal. La corriente lateral presenta numerosas sustancias citotóxicas: hidrocarburos aromáticos, policíclicos, aminas aromáticas, nitrosaminas, metales pesados, gases venenosos, residuos de pesticidas, elementos radioactivos, cadmio, benzopireno y nicotina, muchos de ellos en mayor cantidad que la corriente principal $^{9}$, aunque luego se diluye.

Parece que la nicotina y los metales pesados tienen un papel importante en la génesis del tumor ${ }^{10}$; los tóxicos se bañan en la sangre renal y luego se excretan por orina. Se ha visto en ratas expuestas a humo del tabaco ambiental que se produce daño en el $A D N$ en células de vejiga y riñón por la excreción química en orina de estos productos, contribuyendo así al proceso carcinogenético en estos órganos ${ }^{11}$. También se ha visto en sus fetos un aumento de 8-oxo-desoxiguanina, marcador del daño oxidativo en el ADN en riñón de la madre y el feto $^{12}$.

En el fumador activo se observa un aumento progresivo del riesgo con acumulación de dosis (paquete-años) ${ }^{13}$, es posible que en el fumador pasivo ocurra del mismo modo. La paciente del caso presentó dos carcinomas distintos de mama y riñón; ambos tienen relación documentada con el tabaco. La paciente convivió en un espacio muy reducido con 3 fumadores de cantidades importantes de cigarrillos y durante gran parte de su vida. Dejamos para la reflexión si debemos incorporar el consejo antitabaco en el hogar, para aumentar la protección de los convivientes con fumadores.

\section{AGRADECIMIENTOS}

Queremos agradecer la ayuda prestada por África García Pérez y Belén González Naveso, adminis- trativos del Servicio de Radiología del Centro de Salud María Ángeles López Gómez.

\section{BIBLIOGRAFÍA}

1. Samet JM. Los riesgos del tabaquismo activo y pasivo. Salud Publica Mex. 2002; 44 (Supl 1): S144-S160.

2. Fernández Ferré ML, Gual Solé A, Cabezas Peña C. Drogodependencias. En: Martin Zurro A, Cano Pérez JF, edits. Atención Primaria. Conceptos, organización y práctica clínica. $4^{a}$ ed. Madrid: Harcourt Brace España; 1999, p. 70519.

3. Suárez-Bonel MP, Sartolo-Romeo MT, Sáenz-Lafuente L, Villaverde-Royo MV, Córdoba-García R. Prevalencia y percepción sobre el tabaquismo pasivo en usuarios de atención primaria. Semergen. 2011; 37 (1): 8-14.

4. Fernández E, Schiaffino A, Peris M. Tabaquismo en mujeres: un problema de salud emergente. Enf Emerg. 2001; 3 (4): 184-90.

5. Bravo Troncoso B, Clavello Fiorini A. El impacto del tabaquismo sobre el riñón y el aparato genitourinario. Med Intena Méx, 1997; 13 (2): 82-7.

6. Hunt JD, van der Hel OL, McMillan GP, Boffetta P, Brennan P. Renal cell carcinoma in relation to cigarette smoking: Meta-analysis of 24 studies. Int J Cancer. 2005; 114 (1): 101-8.

7. Luo J, Margolis KL, Wactawski-Wende J, Horn K, Messina $\mathrm{C}$, Stefanick ML et al. Association of active and passive smoking with risk of breast cancer among postmenopausal women: a prospective cohort study. BMJ. 2011; 342:d1016.

8. Nishino Y, Tsubono Y, Tsuji I, Komatsu S, Kanemura S, Nakatsuka $\mathrm{H}$ et al. Passive smoking at home and cancer risk: a population-based prospective study in Japanese nonsmoking women. Cancer Causes Control. 2001; 12 (9): 797-802.

9. Martín Ruiz A, Rodríguez Gómez I, Rubio C, Revert C, Hardisson A. Efectos tóxicos del tabaco. Rev Toxicol. 2004, 21 (2-3): 64-71.

10. Cooper RG. Effect of tobacco smoking on renal function. Indian J Med Res. 2006; 124 (3): 261-8.

11. Takenawa J, Kaneko Y, Okumura K, Nakayama H, Fujita $\mathrm{J}$, Yoshida O. Urinary excretion of mutagens and covalent DNA damage induced in the bladder and kidney after passive smoking in rats. Urol Res. 1994; 22 (2): 93-7.

12. Maciag A, Bialkowska A, Espiritu I, Powell D, Alvord WG, Kasprzak $\mathrm{K}$ et al. Gestation stage-specific oxidative deoxyribonucleic acid damage from sidestream smoke in pregnant rats and their fetuses. Arch Environ Health. 2003; 58 (4): 238-44

13. Brennan P, Van der Hel O, Moore LE, Zaridze D, Matveev V, Holcatova I et al. Tobacco smoking, body mass index, hypertension, and kidney cancer risk in central and eastern Europe. Br J Cancer. 2008; 99 (11): 1912-5. 